\title{
Obituary
}

\section{Dr Montague Joyston-Bechal}

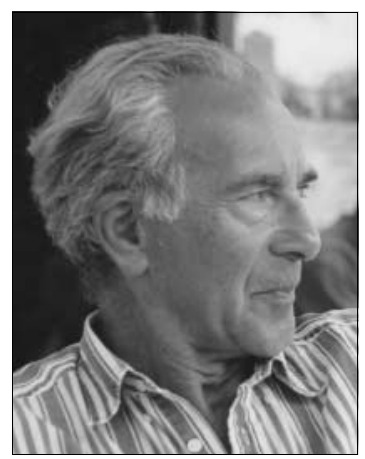

Formerly Consultant Psychiatrist, Central Middlesex Hospital, London

Montague Joyston-Bechal, FRCP, FRCPsych, DPM, was a psychiatrist whose temperament fitted him well for his chosen career. He was by nature curious about the human condition but with a curiosity tempered by compassion, courtesy, humour and abounding empathy, so it was small wonder that as a clinician he was held in high and affectionate esteem by patients and colleagues alike.

Montague was born on 26 April 1930 and went to Merchant Taylors School. In 1948 he went up as a medical student to Queen's College, Oxford, where he cut a more dashing figure than many of his contemporaries. He acted, and gave parties which Kenneth Tynan might attend. Despite these distractions he completed his pre-clinical studies and obtained a degree in physiology with seeming effortlessness. He proceeded to clinical training at the Westminster Hospital where he played the lead in Hospital pantomimes, and qualified BM BCh in 1954. National Service followed as an RAF medical officer in Sri Lanka, which allowed him to act as medical officer during the filming of Bridge on the River Kwai, a posting which Montague much enjoyed. On demobilisation he took a 6-month GP appointment job in Australia, married Sally, whom he met in Perth, and came back to London. Having passed the MRCP he enrolled in the intellectually demanding 3-year postgraduate psychiatry training at the Maudsley.

At the Maudsley, Montague made lasting friendships with a number of contemporaries - a capacity for friendship was another of his prime gifts. Having qualified in psychiatry with the academic DPM, he held a senior registrar position at the London Hospital before being appointed consultant at Shenley in 1967, and held appointments at Edgware General and the Wembley Hospital. In 1974, he was appointed consultant psychiatrist at the Central Middlesex Hospital, where he gave the next 16 years of his professional life to nurturing his clinical base at the Central Middlesex, and to the generous giving of himself and his skills to his patients and to the junior staff who trained under him. He gave his time to numerous hospital committees.

There was also still the party goer, the good conversationalist, the man who kept up with a cultural life, but that never diminished his commitment to the NHS. He was a general psychiatrist with a specialty in psychotherapy and sexual problems. He developed a successful private practice and expertise in medico-legal work, with those activities continuing after his retirement from the NHS in 1990 and up to his 79th year. His publications included a paper written in 1966 on the puzzling condition of stupor.

Those of us who had the privilege of knowing Montague personally, are likely to assert that he exemplified what his profession in important ways should at the very best be about. Beyond that professional distinction we will remember him for his boundless and multiple wider enthusiasms - London life, trout fishing in Oxfordshire, literary festivals attended, a love of jazz, wide travel, a taste for fine beer. He could strike up a friendly conversation with any stranger met. His marriage to Sally, who after a career in academic dentistry established herself as a successful sculptor, added incomparably to the richness of his life. He died on 25 February 2009. He is survived by Sally, his two sons and daughters-in-law, and three grandchildren who further contribute to a happy circle of family life.

doi: 10.1192/pb.bp.109.028654
Griffith Edwards

\section{Reviews}

\section{Memory: A Very Short Introduction \\ Jonathon K. Foster \\ Oxford University Press, 2008, $€ 7.99$ pb, 144 pp. \\ ISBN 9780192806758}

A number of titles from Oxford's short introduction series already occupy my bookshelf. One of the series' attractions is that it makes academic material easily accessible. The latest addition by Foster addresses memory and does not deviate from the formula.

Foster successfully conveys the past and present understanding of the inner workings and structure of our memory. He presents interesting challenges to test ones memory; I was surprised that I could not remember specific details of objects I handle daily, such as coins. Through invoking such reactions, deficiencies in our memory are convincingly highlighted.
His use of apt vignettes throughout is engaging and of interest from a clinician's perspective. The case is told of Donald Thompson. He was accused of rape; however, he was participating in a televised debate at the supposed time of the rape. He was obviously innocent. The rape was committed while the afore-mentioned debate was coincidently showing on the victim's television at the time and the false accusation was actually due to the phenomenon of 'source amnesia'.

There are excellent summaries on scientific studies from the viewpoints of their proponents and opponents. The apparent ease with which these can be understood is a testament to the author's skill. At times, however, my own memory seemed to fail. With the introduction of many similar sounding terms, on occasion I had to refer to their original descriptions. Perhaps a glossary would have helped in this regard.

This book does not pretend to be a text on memory that would be of use to psychiatrists. However, it presents material 
that is of universal relevance and provides insight into an important topic. It offers plentiful direction to further resources and has a practical, useful section on improving memory. Memory will be a welcome addition to my collection of short introductions.

Dr Zahir Mirza, Academic Foundation Year 2 House Officer, Heartlands Hospital, Bordesley Green East, Birmingham B9 5SS, email: zahirmirza@nhs.net

doi: $10.1192 / p b . b p .109 .024828$

\section{Clinical Skills in Psychiatric Treatment}

Rob Poole \& Robert Higgo

Cambridge University Press, 2008, $€ 36.00$ pb, 240 pp. ISBN 9780521705707

I sincerely recommend this book, although with a few qualifications. In an era of rapid change in psychiatry with an explosion in types of therapies and models of service delivery, it takes us back to the basics which can otherwise feel lost in the detail. The key to being a good psychiatrist is in knowing how to treat patients rather than simply what to treat them with, and a book focusing on the former is therefore welcome. Clinical Skills in Psychiatric Treatment is an honest, reflective and often humorous endeavour by experienced consultant psychiatrists to help others share their wisdom and learn from their mistakes.

The book is about how to do simple things thoughtfully and effectively, starting with the underlying principles of treating patients. The discussion then moves on to the environments where treatment take place, looking at what makes for effective teamwork, and thinking about how to optimise the benefit $v$. risk of situations such as in-patient environments and legal compulsion. The latter part of the book focuses on common problems, risks and dilemmas in treatment, and gives practical advice on how to tackle them productively.

From the outset the book uses a style of language which is refreshingly frank and clear. Patients are called patients, not users, clients or consumers. Concepts are described which are pragmatic and meaningful, for example the authors talk about 'getting alongside patients' in order to understand what their illness means to them and how to help them recover. They value the importance of patients 'taking responsibility' for getting better rather than dwelling on whether or not they have 'insight' into specific delusional beliefs.

The book gives practical advice on various aspects of psychiatric treatment and this is its major strength. The points made are often refreshingly simple but their importance resonates in well-chosen case histories such as the example illustrating strategic $v$. reactive management of a clinical scenario. There is other good advice, for example treating patients in context and anticipating and evaluating setbacks, but the book also encourages the reader to reflect on how they practice, such as thinking about the need to move between different models of care during different phases of a patient's treatment these models being described as 'paternalistic' $v$. 'patient as consumer'.

There are some obvious criticisms, the style can be bumptious and may be off-putting for some. The authors can be provocative (e.g. 'second opinions are rarely helpful, except as a defensive manoeuvre'), but they give clear reasons for such statements which provide food for thought. The views expressed can be excessively polarised, for example saying out-patient clinics are outmoded may well be appropriate in assertive outreach models of care but ignores the fact that clinics remain an important component of generic community mental health teams' work. The discourse on the Mental Health Act is unfortunately out of date, and the authors may have been better steering clear of the debate, knowing that new legislation incorporating supervised community treatment was imminent.

In my view, this book should be on the reading list of psychiatric trainees. It is engaging, wise, stimulating and patient centred. It does not by any means ignore scientific developments in the field, but it puts empathy, reason and pragmatism at the core of clinical practice, and thus establishes a sound base upon which to practice good psychiatry.

Rowena Jones Early Intervention Service, Birmingham \& Solihull Mental Health Foundation Trust, Miller Street, Aston, Birmingham, email: rowena.jones@btinternet.com

doi: $10.1192 /$ pb.bp.109.025973

\section{MRCPsych: Passing the CASC Exam}

Justin Sauer (ed.)

Hodder and Stoughton, 2009, £24.99 pb, 288 pp. ISBN 9780340981948

The recent changes in the delivery of mental healthcare, including the introduction of functional teams, appears to have fragmented service delivery. This has been accompanied by a fragmentation of knowledge in the form of competency-based assessments. This resulted in competencies that are difficult to measure being ignored. The Clinical Assessment of Competencies and Skills (CASC), especially the linked CASC, are probably the most advanced forms of competency-based assessments. They offer considerable semblance to normal clinical practice.

Since the introduction of the linked CASC in the MRCPsych exams, there has been a relatively unmet need for books for candidates preparing for these exams. Justin Saucer and his team have successfully filled this gap. This book presents more than 100 CASC stations, both linked and standalone, covering all subspecialties of psychiatry, including physical examination and investigations. The stations are well referenced and have many useful tips for candidates. The editor has ensured that all the contributors follow the same format. Every station is systematically organised under the headings 'key points', 'set the scene', 'completing the tasks', 'problem solving' and 'additional points'. The impressive front cover would make the reader feel like being a doctor again.

The organisation of the book sometimes makes it difficult to navigate through. For example, some answers appear 20-30 pages after the question. Although it would increase the number of pages, starting every station on a new page would have been more reader friendly. Candidates sitting the MRCPsych CASC exams do have to remember that books, however good they are, cannot substitute, but can only compliment, clinical skills and experience.

Overall, this is an excellent revision book that would help candidates increase their chances of passing the MRCPsych CASC exams.

Albert Michael, Consultant Psychiatrist and Director of Medical Education, Suffolk Mental Health Partnership NHS Trust, email: albert.michael@smhp.nhs.uk doi: 10.1192/pb.bp.109.027144 